\title{
Antipsychotic Measurement
}

National Cancer Institute

\section{Source}

National Cancer Institute. Antipsychotic Measurement. NCI Thesaurus. Code C75344.

The determination of the amount of any antipsychotic drug present in a sample. 